\title{
Influence of the anti-erosion complex on erosion-hydrological indicators and productivity of cultivated crops
}

\author{
Igor Podlesnyh ${ }^{1 *}$, Tatyana Zarudnaya ${ }^{1}$, Anastasya Prushchik $^{1}$, and Sergey Tarasov ${ }^{1}$ \\ ${ }^{1}$ FSBSI "Federal Agricultural Kursk Research Center" 70b, Karl Marx St., Kursk, 305021, Russia
}

\begin{abstract}
An assessment of the impact of the anti-erosion complex on the productivity of cultivated crops has presented on the example of many years of experience in contour-ameliorative agriculture of the Kursk FARC located in the northern part of the Medvensky district of the Kursk region. Two subtypes of chernozem represent the soil of the experiment: typical and leached. As anti-erosion measures, narrow-row stock-regulating poplar forest belts, reinforced by a simple hydraulic structure (ditch and rampart along the lower edge), have designed and planted along the contour at a distance of $216 \mathrm{~m}$. There are no anti-erosion measures in the control catchment. Analysis of long-term data showed a decrease in runoff and the absence of soil washout in the catchment area with a system of narrow-row forest belts 38 years after the experiment has laid in comparison with the control. For the control catchment, a maximum soil washing of $22 \mathrm{t} / \mathrm{ha}$ recorded which significantly exceeds the permissible standards of flush. A significant increase in crop productivity averaged 5.2 feed units. The profitability of growing crops in fields with forest belts exceeds the control by almost $50 \%$. The anti-erosion complex performs the task of strengthening the soil-protective role of the farming system.
\end{abstract}

Keywords: Soil erosion, snow melting, forest belts, productivity of agricultural crops, erosion and hydrological indicators, anti-erosion complex.

\section{Introduction}

Soil erosion is a global problem for humanity. Because of irrational economic activity, erosion processes have taken on catastrophic proportions throughout the planet. 23 billion tons of soil is lost in the world every year [1-3]. In Russia, this figure averages more than $4 \mathrm{t} /$ ha per year of fertile arable soil [4-6].

Erosional losses have rightfully considered nonrenewable, because it is impossible to restore the washedout soil layer in the same time, after which it was lost [7, $8]$.

Researchers have found that eroded soils are less fertile than non-eroded ones, have worse physical and chemical properties, have a lower humus content, a lower percentage of the agronomical valuable structure of the arable horizon and a more blocky structure due to plowing of the underlying layers [9].

The decline in crop yields is directly proportional to the degree of soil erosion. It is possible temporarily increase yields on eroded soils with the help of fertilization, but not all crops are responsive to increased application of fertilizers or the use of more productive varieties. However, the profitability of growing crops on eroded soils is lower than on non-eroded soils [10-14].

Therefore, it is relevant to conduct rational economic activities with the prevention of negative anthropogenic impact on the soil under arable land. The introduction of a contour-reclamation approach in land management of agricultural lands based on an adaptive-landscape farming system is an effective way to combat water erosion of soils and increase the productivity of cultivated crops. Fields surrounded by forest shelterbelts have a microclimate that favorably affects the growth and development of agricultural crops in comparison with open fields and fields outside the zone of forest belts [1519].

Planting water-regulating forest belts allows you to correct snow distribution, reduce the flow of melt water, significantly reduce or completely eliminate soil flushing [20]. These results are achieve due to several factors: firstly, forest belts divide the slope into short sections, thereby reducing the speed of flowing water; secondly, under forest belts, especially with the use of hydraulic structures, for example, reinforced with a ditch and a rampart along the lower edge, the absorption capacity of the soil is higher than in the field located above and below this strip. Substantiated arrangement of elements of antierosion line boundaries allows not only to reduce soil erosion losses, but also to increase the yield of cultivated crops $[21,22]$.

In the Kursk region, arable soils are located mainly on the slopes, where, from the beginning of farming, they have exposed to accelerated water erosion [23]. Therefore, it is relevant to obtain information on the effectiveness of the effect of the anti-erosion complex with water-regulating forest belts on the productivity of agricultural crops as the forest belts develop and grow.

The purpose of the research is to assess the impact of water-regulating forest belts on erosion-hydrological 
indicators and the productivity of cultivated crops in longterm experience in contour-reclamation agriculture.

\section{Materials and methods}

The research has carried out in the northern part of the Medvensky district of the Kursk region on a stationary experiment on contour-reclamation agriculture of the FSBSI Kursk FARC. The experience has monitored for 38 years since its inception. The time of trenching in the aisle of the forest belt - 1986. Before carrying out contour-reclamation measures, the soil of the experiment was under intensive agricultural load.

The slope of the western exposure of the catchment without the use of anti-erosion measures has chosen as a control. The length of the experimental slope was $800 \mathrm{~m}$ with a varying slope ranging from 1 to 5 degrees. Area 41.5 hectares. Coordinates: $51^{\circ} 31^{\prime} 18.0^{\prime \prime} \mathrm{N} 36^{\circ} 02^{\prime} 29.4^{\prime \prime} \mathrm{E}$ 51.521665, 36.041488 (Fig.1).

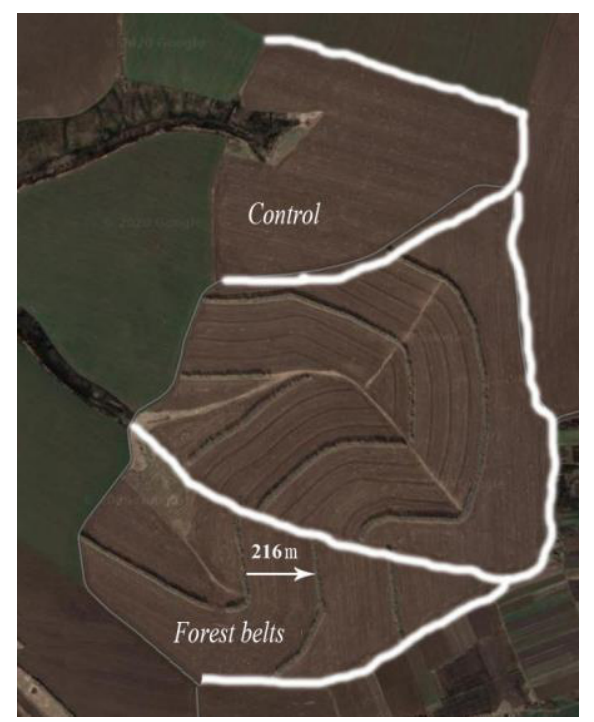

Fig. 1. Studied catchments (Medvensky district, Kursk region)

To study the effect of anti-erosion measures, the slope of the western exposure of the catchment was investigated, on which narrow two-row water-regulating forest belts were designed and planted, reinforced with a ditch between the rows and a rampart along the lower edge. Forest belts are located at a distance of $216 \mathrm{~m}$ from each other. In total, there are 3 linear anti-erosion boundaries on the slope. The length of the slope was 1100 $\mathrm{m}$. The slope varied down the slope from 1 to 5 degrees. The catchment area is 46.4 hectares. Coordinates: $51^{\circ}$ 30'36.6 "N 36 02'22.1" E 51.510175, 36.039466 (Fig. 1).

Based on the experience of contour-reclamation agriculture, the species composition of forest belts is mainly represented by a hybrid of the Euro-American Robusta poplar (Populus euramericana Robusta) and black poplar (Populus nigra L.), characterized by rapid growth at the beginning of the growing season (1-1.5 m annually) and a gradual decrease from age $(0.5 \mathrm{~m}$ per year), conical closed crown. The row spacing during planting was set $3 \mathrm{~m}$.
On the experimental plot, the predominant soil is two subtypes of chernozem (Haplic Chernozem). Chernozems typical migratory-mycelial medium-thick heavy loamy on loess-like loams with the profile formula PU-PU $-A$ $\mathrm{AB}_{\mathrm{ca}}-\mathrm{B}_{\mathrm{ca}}-\mathrm{BC}_{\mathrm{ca}}-\mathrm{C}_{\mathrm{ca}}$ in combination with leached chernozem (Chernozems leached) medium-thick heavy loamy on loess-like loams with the profile formula PU$\mathrm{PU}_{1}-\mathrm{A}-\mathrm{AB}-\mathrm{B}-\mathrm{BC}_{\mathrm{ca}}-\mathrm{C}_{\mathrm{ca}}$.

Soil flushing has taken into account by measuring algae [24-25].

To monitor atmospheric precipitation, the Tretyakov rain gauge has used, located between the studied catchments on the watershed plateau.

The depth of freezing and thawing of the soil was determined with permafrost meters designed by Danilin, which have installed in October and took readings every ten days until the end of March in both catchments from top to bottom along the slope profile.

The depth of the snow cover was determined during snow surveying along a pre-built route used annually. At the same time, the water content in the snow was determined before the beginning of snow melting.

Soil moisture have taken layer by layer with an AM16 soil drill to a depth of $1 \mathrm{~m}$, and was determined according to GOST 28268-89 by the thermostat-weight method [26]. The selection of soil for moisture have carried out before the beginning of snow melting, before sowing, according to the phenophases of the culture and after harvesting.

In the past two decades, a shortened grain crop rotation has been cultivated experimentally: winter wheat (Triticum aestivum L.) - buckwheat (Fagopyrum esculentum) - spring barley (Hordeum distichon L.) buckwheat (Fagopyrum esculentum) and grass-grain crop rotation): spring barley (Hordeum distichon L.) with oversowing of perennial grasses - perennial grasses (Bromopsis inermis Holub) 1 year of use - perennial grasses (Bromopsis inermis Holub) of 2 years use). Awless rump (Bromopsis inermis Holub) have sown as perennial grasses.

The technology of cultivation of crops grown in crop rotations, generally accepted for the Kursk region of the Russian Federation, is the same within the crop rotation in all experience.

Yield counting have carried out by the method of continuous counting on test sites in accordance with GOST 27548-97.

The data have processed by the method of analysis of variance [27].

\section{Results and Discussion}

To study the effect of the anti-erosion complex, we selected contrasting weather conditions and relatively evenly spaced time intervals during the course of the experiment, focused mainly on the cultivation of winter wheat during the study.

1986 is the closest year to the establishment of the experiment and planting of narrow-row stock-regulating forest belts; therefore, the effect of the anti-erosion complex was practically absent. 
1994 is the year with the lowest temperature in the autumn-winter period and a high volume of runoff and soil washout during spring snowmelt.

2010 is characterized as quite hot and dry, the most unfavorable for the cultivation of winter wheat.

2020 was a favorable year for the cultivation of winter wheat and the most distant in time from the beginning of the experiment.

According to D.V. Dubovik and D.Yu. Vinogradov [28], the overwintering conditions for winter wheat plants have a significant effect on the productivity of the crop. Moreover, a decrease in the productivity of winter wheat was noted when the average monthly temperature exceeded the average annual rate. Therefore, when analyzing the agro meteorological conditions of the years under study, we took into account the average monthly air temperature and the amount of precipitation during exposure to negative temperatures (from October to March) (Figure 2-3).

The years under study differed in temperature. The warmest year was 2020; the average monthly temperature in January and February was negative, but still exceeded the average annual indicators by $20 \%$. The winter wheat yield was also significantly higher in 2020 compared to the rest of the years. Temperature for the cold period of 1994 and 2010 was 10\% lower than the long-term average.

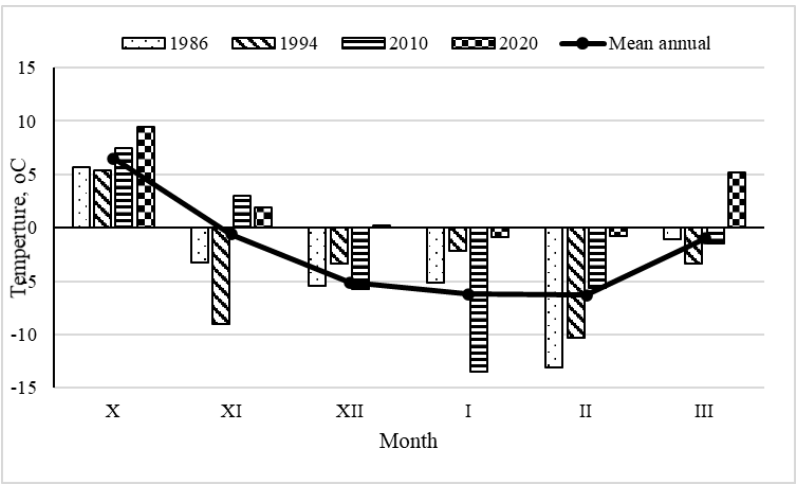

Fig. 2. Average monthly temperature by years

The amount of precipitation for the years under study, on average, did not significantly differ from the average annual precipitation, varying significantly in individual months.

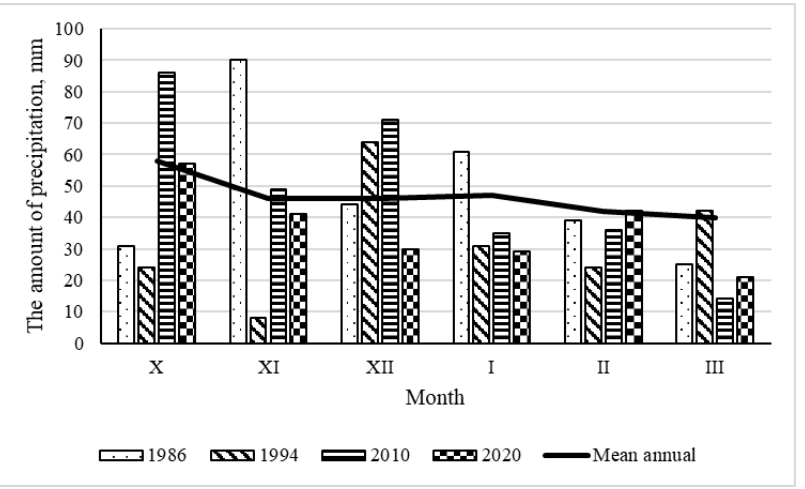

Fig. 3. The amount of precipitation over the years.
The depth of soil freezing depends on the temperature and precipitation in the autumn-winter period.

The depth of soil freezing varied over the years of the experiment; a high rate was recorded in $1986(88.3 \pm 1.3$ $\mathrm{cm}$ ) in both catchments. The large freezing depth in the catchment with the anti-erosion complex has explained by the low height of young trees in the forest belt, which could not create favorable microclimatic conditions for the entire catchment. For the rest of the years, there is a positive trend towards a decrease in soil freezing in the catchment area with forest belts compared to the control.

According to A.T. Barabanov. [24] when the soil freezes to a depth of less than $50 \mathrm{~cm}$, runoff has formed. The dependence of soil flushing on the depth of freezing is in a close direct relationship by years (1986, 1994, 2010, 2018, 2020) (Fig. 4).

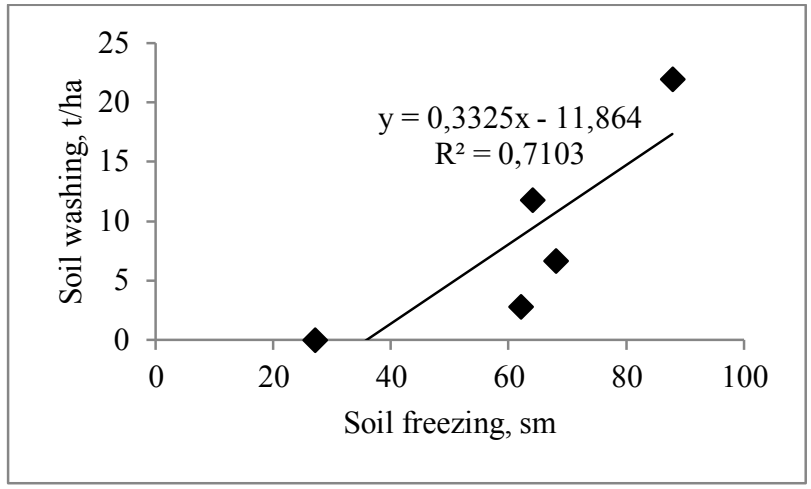

Fig.4. Dependence of soil washing on the freezing depth

Due to a significant excess of the average monthly temperature in 2020, from October to March, a stable snow cover did not form, the freezing depth in the control catchment was $27 \pm 3 \mathrm{~cm}$. There was no drain. Therefore, 2018 was added to Figure 5.

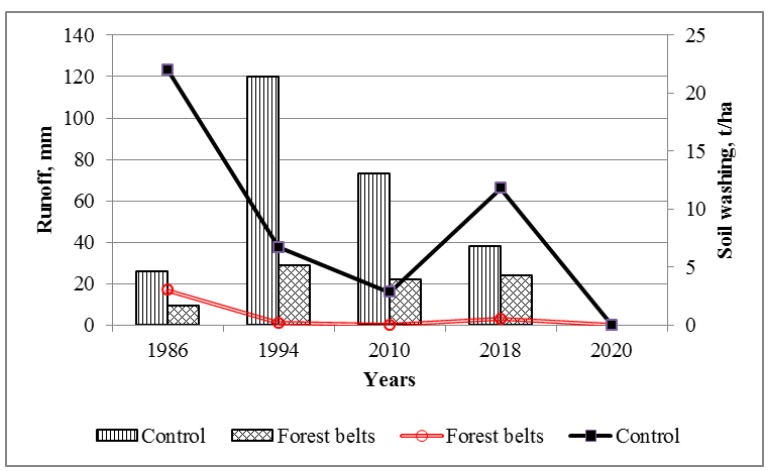

Fig. 5. Runoff and soil washing over the years

Analysis of the data shows that soil washout in the control catchment is higher in all studied years. The highest rates had recorded in 1986 and 2018.

Kuznetsov M.S. and Abdulkhanova D.R. [29] when calculating the permissible limits of losses, it was found that on typical chernozem, the permissible rate of soil washout can reach $9 \mathrm{t} / \mathrm{ha}$. During the studied period, on the experiment on contour-reclamation agriculture, soil washout exceeding the permissible losses in 1986 and 2018 have recorded in the control variant. During the experiment, the maximum soil washout in the catchment 
with water-regulating forest belts was recorded only in 1986, 3 t/ha. Consequently, in 1986, a system of young forest belts, reinforced with a ditch in the row-spacing and a rampart along the lower edge, was able to reduce soil washout in the catchment compared to the control by 7 times. The value of runoff was significantly different only in 1994 and 2018 years, other years differ insignificantly.

The influence of erosion control measures (forest belts) on the productivity of agricultural crops have presented in Table 1.

Table 1. Average productivity (food units) by catchments in selected years

\begin{tabular}{|c|c|c|c|}
\hline Years & Control & $\begin{array}{c}\text { The catchment } \\
\text { area with forest } \\
\text { belts }\end{array}$ & $\begin{array}{c}\text { Increase, } \\
+/-\end{array}$ \\
\hline 1986 & 50.1 & 52.4 & 2.3 \\
\hline 1994 & 49.0 & 54.3 & 5.3 \\
\hline 2010 & 26.6 & 33.0 & 6.4 \\
\hline 2020 & 59.8 & 66.8 & 7.0 \\
\hline Average & 46.5 & 51.6 & 5.2 \\
\hline NSR $_{\mathbf{0 5}}$ & \multicolumn{3}{|c}{} \\
\hline
\end{tabular}

Analysis of the productivity of the crop in the catchment area with water-regulating forest belts and control showed its significant increase even in the first years after planting. An increase in productivity in the catchment area with forest belts has observed even in the extremely dry year of 2010 , due to the creation of a microclimate in the field with a water-regulating forest belt.

The assessment of the profitability of winter wheat cultivation for two catchments, calculated at prices of 2020 (Fig. 6) shows a stable increase of it by $50 \%$ compared to the control.

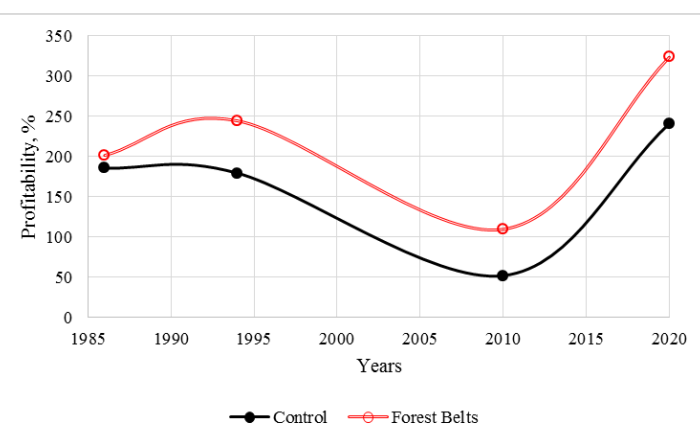

Fig. 6. Profitability of crops cultivation by years

Although in the first years after planting forest belts, the profitability differed insignificantly, the increase in productivity was reliably positive.

\section{Conclusion.}

Over a long-term observation period, a positive effect of anti-erosion measures in the form of forest belts on erosion-hydrological indicators was established.

A decrease in runoff during snowmelt has noted, and there was no soil washout in the catchment area with a system of forest belts. There is a stable trend towards an increase in crop productivity, which has confirmed by economic calculations.

The work was carried out within the framework of the Statetasks of FSBSI «Federal Agricultural Kursk Research Center» on topic No. 0632-2019-0017.

The team of authors would like to thank Yu.P. Sukhanovsky for advice in the field of erosionhydrological processes and to the leading researcher of the laboratory of agro chemistry and GIS G.P. Glazunov for scientific and methodological assistance in writing the article.

\section{References}

1. P. Borrelli, D.A. Robinson, L.R. Fleischer, E. Lugato, C. Ballabio, Ch. Alewell, K. Meusburger, S. Modugno, B. Schutt, V. Ferro, V. Bagarello, K.V. Oost, L. Montanarella, P. Panagos, Nat Commun 8(1) (2017).

2. V. Golosov, N. Ivanova \& S. Kurbanova, Int. J. of Sediment Research 32(1), 60-72 (2017)

3. H.O. Shen, W.T. Zhao, Y. Zhang, D.L. Wang \& L.L. Wen, Eurasian Soil sc. 53(10), 1509-1519 (2020)

4. K. Maltsev \& O. Yermolaev, Catena 195, 104726 (2020)

5. P. Krasilnikov, O. Makarov, I. Alyabina \& F. Nachtergaele Geoderma Reg. 7(1), 1-10 (2016)

6. L.F. Litvin, Z.P. Kiryukhina, S.F. Krasnov \& N.G. Dobrovol'skaya, Eurasian Soil Sc., 50 (11) 13441353 (2017)

7. P. Tsymbarovich, G. Kust, M. Kumani, V. Golosov, O. Andreeva, Inter. Soil and Water Conservation Research 8(4), 418-429 (2020)

8. V.N. Golosov, A.L. Collins, N.G. Dobrovolskaya, O.I. Bazhenova, Yu.V. Ryzhov, A.Yu. Sidorchuk, Geoderma 381, 114678 (2021)

9. E.V. Dubovik, Eurasian Soil sc. 45(3), 303-308 (2012)

10. S.I. Sanzarova, Yu.P. Sukhanovskii \& A.V. Prushchik, Plodorodie 5(50), 39-40 (2009)

11. H. Kumar \& P. Pani, J. of Rural Development 32: 165-184 (2012)

12. M.M. Bakker, G. Govers, R.A. Jones \& D.A.R. Mark Ecosystems 10, 1209-1219 (2007)

13. N.N. Tsybul'ka, L.A. Tishuk, A.V. Yukhnovets, Eurasian Soil sc. 35(12), 1315-1321 (2002)

14. F. Negash, T. Mulualem \& K. Fikirie, Adv. Crop. Sci. Tech 6, 326 (2018)

15. S. Puri \& P.K.R. Nair, New Vistas in Agroforestry. Advances in Agroforestry 1 (Springer, Dordrecht, 2004).

16. V.D. Postolov, V.A. Temnyshova, V.V. Lyutova, Vestnik Voronez GAU 2(37), 351-357 (2013)

17. S.Y. Bulygin, Eurasian Soil sc. 31(4) 429-435 (1998)

18. I.M. Gabbasova, R.R. Suleimanov, M.A. Komissarov, T.T. Garipov, L.V. Sidorova, F.K. Khaziev, I.K. Khabirov, M. Fruehauf \& P. Liebelt, Eurasian Soil sc. 49(10), 1204-1210 (2016)

19. Sokolova G., IOP Conference Series: Earth and Environmental Sc. 723, 032092 (2021) 
20. A.T. Barabanov, A.I. Petel'ko, A.V. Kulik \& A.V. Vipova, Izv. Nizhnevolzh. Agrouniversit. kompleksa: nauka i VPO 2(54), 119-126 (2019)

21. V.A. Cilova, Nauchnyy J Rossiyskogo NII problem melioratsii 11(2), 68-81 (2021)

22. V.I. Erusalimskii, V.A. Rozhkov, Dokuchaev Soil Bull. 88, 121-137 (2017)

23. Yu.P. Sukhanovskii, A.V. Prushchik \& S.I. Sanzarova, Vestnik Kursk GSKHA 6, 53-59 (2013)

24. A.T. Barabanov, Nauchno-agronom. J. 1(1), 108 (2020)

25. A.P. Zhidkin, V.N. Golosov, A.A. Svetlichny, A.V. Pyatkova, Geomorfologiya 2, 41-53 (2015)

26. A.F.Vadyunina, Z.A. Korchagina, Methods of research of physical properties of soils (M., Agropromizdat, 1986)

27. B.A. Dospekhov, Methods of experimental work (M., Agropromizdat, 1985)

28. D.V. Dubovik, D.Yu. Vinogradov, Dostiz. nauki i tekhn. APK 5, 23-24 (2013)

29. M.S. Kuznetsov, D.R. Abdulkhanova, Eurasian Soil sc. 46(7), 802-809 (2013) 